\title{
The foramen ovale from the fetal to neonatal life span
}

\author{
Monika Wójtowicz-Marzec \\ Department of Obstetrics and Pathology of Pregnancy, Medical University of Lublin, Poland
}

\section{ABSTRACT}

The foramen ovale is an important structure that ensures the functioning of the fetal circulatory system. The work describes process of atrial septum formation from the embryonic stage to the neonatal period. Human atrial septation is inefficient process resulting in a persistent foramen ovale in quarter of adult population. Imaging of the foramen ovale is a valuable parameter for the assessment of the fetal circulatory system with the possibility of capturing life-threatening conditions. The dynamic process of adaptation to extrauterine life is also reflected at the foramen ovale in the postnatal period. The persistent foramen ovale is usually clinically silent in the pediatric population, while in the perspective of adulthood it may be a factor contributing to thromboembolic stroke. The aim of this article is to describe the essential differences in the function of the foramen ovale in the fetal and neonatal period.

\section{KEY WORDS:}

echocardiography, neonatal period, interatrial septum, foramen ovale, fetal cardiovascular function.

\section{INTRODUCTION}

For this review, a thorough literature search was repeatedly performed in PubMed and Medline, including only articles written in the English and Polish languages. The following search terms were used: atrial septum, embryology of interatrial septum, foramen ovale, fetal cardiovascular function, and echocardiography.

\section{DEVELOPMENT OF ATRIAL SEPTATION}

Atrial septation is a long and complicated process during the ontogenetic development of the human heart. Septation starts in the fourth week of gestation, but it is not completed until after birth, when the secondary septum merges with the primary septum [1-5]. The membranous tissue forming the septum primum grows from the roof of the atrium, dividing it into left and right halves. The leading edge of the primary atrial septum, covered with the mesenchymal cap, approaches the atrioventricular cushions, which themselves are in the process of fusing.
The foramen primum refers to the decreasing communication between the septum primum and the endocardial cushions. It is interesting that the myocardium of the primary atrial septum is part of the left atrial expression domain, and the orifice of the pulmonary veins is also surrounded by myocardium with a left atrial molecular phenotype. The completion of the fusion of the mesenchymal tissues at 6-7 weeks of development results in the closure of the primary interatrial foramen [5]. The junction of the septum primum and the endocardial cushions becomes myocardialized by ingrowth of myocardial cells, although the centre is maintained as a dense connective tissue, being referred to as the tendon of Todaro. Apoptosis-induced perforations appear in the centre of the septum primum to produce the foramen secundum [6]. The secondary atrial septum is formed as a result of an infolding of the atrial roof. At this point, the strong muscular septum secundum grows immediately to the right of the septum primum, and then gradually overlaps the foramen secundum during the fifth and sixth weeks of development. Parts of the atrial septum and the dorsal right atrium, as well as

\section{ADDRESS FOR CORRESPONDENCE:}

Monika Wójtowicz-Marzec, Department of Obstetrics and Pathology of Pregnancy, Medical University

of Lublin, Jaczewskiego 8, 20-954 Lublin, Poland, e-mail: monikawmarzec@gmail.com 
A

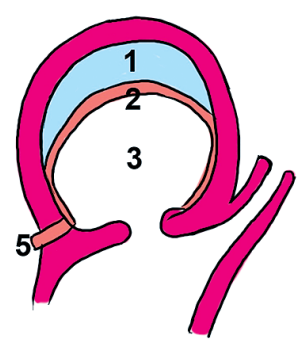

$\mathrm{E}$

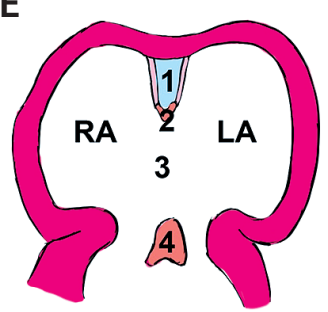

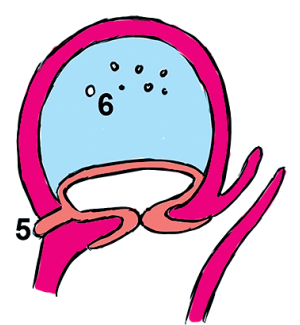

$\mathrm{F}$

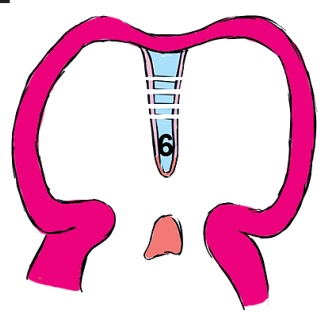

C

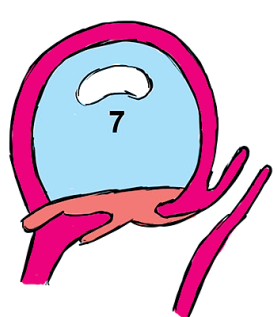

G

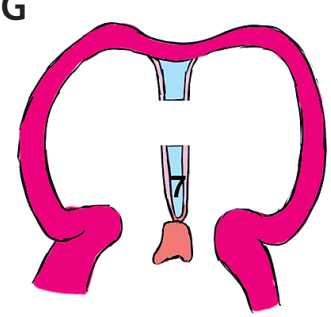

D

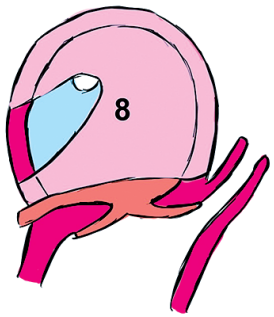

$\mathrm{H}$

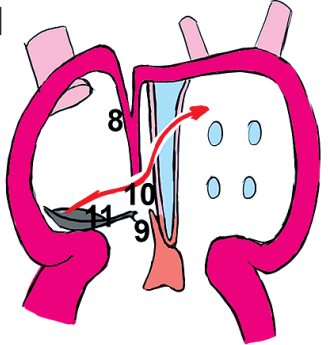

FIGURE 1. A process of normal atrial septation in the sagittal view (A-D) and the four-chamber view (E-H). (A) The primary septum (1) initiates from the mesenchymal cap (2), beneath the atrial roof is the primary foramen (3) and the cushions of the atrioventricular canal. The septum grows towards the atrioventricular cushions (4). The dorsal mesocardium (5) contributes to the dorsal mesenchymal protrusion to the atrial cavity. The primary foramen is closed by a merger of the mesenchymal cap, the dorsal mesenchymal protrusion and the atrioventricular cushion. Meanwhile, secondary perforations (6) expand in the primary septum to form the secondary foramen (7). The atrial roof folds (8) inwards on the right atrial side and the mesenchyme of the mesenchymal cap and the dorsal mesenchymal protrusion differentiates into myocardium (9), and then it grows and to form the rim of the foramen ovale (10). The valve of the inferior vena cava (the Eustachian valve (11)) redirects the bloodstream from the ductus venosus preferentially to the lumen foramen ovale

the septum secundum, develop from the left-sided mesenchyme. Based on the gene expression patterns, the left venous valve develops as a myocardial structure with a right atrial molecular phenotype, whereas the right venous valve (just like the secondary atrial septum) develops by infolding, in this case by the junctional tissue between the right atrium and the sinus venosus. The incomplete partition of the atrium by the septum secundum forms the foramen ovale (Fig. 1) [2].

\section{FUNCTION OF THE ATRIAL SEPTUM IN EMBRYONIC AND FOETAL LIFE}

The foetal cardiovascular system is adapted biochemically and structurally to ensure that highly oxygenated blood is delivered preferentially from the placenta to the brain and the heart while being diverted away from the lungs. The combination of the following contributes to the maintenance of the foetal cardiovascular system: biochemical factors, including vasoregulatory agents such as prostaglandins and endothelin-1, and anatomical adaptations such as the presence of 4 shunts: the placenta, the ductus venosus (DV), the ductus arteriosus (DA), and the foramen ovale (FO) (Fig. 2) [5].

\section{FUNCTION OF THE ATRIA IN THE EMBRYONIC PERIOD (UP TO THE $10^{\text {TH }}$ WEEK OF PREGNANCY)}

The human heart in the embryonic phase shows a spontaneous contractile function in the cylindrical phase of the structure at 5 weeks of age (21 days post fertilization). Despite the absence of valves, this structure shows unidirectional blood flow. There are a number of hypotheses trying to explain this phenomenon, including the hypothesis of peristaltic movements, the Liebau phenomenon, and deformation-supporting forces $[8,9]$. The Liebau phenomenon relies on experimental liquid flow in an elastic tube periodically pumped with a finger toward a rigid tube. The direction of liquid flow depends on the pumping site on the elastic tube and is directed to the most closely connected rigid tube. The embryonic heart is a pulsating valveless tube between the large veins (similar to elastic tube in the Liebaus model) and the aorta (similar to the more rigid tube). According to the Liebaus effect, a net flow is generated towards the nearest rigid tube (aorta) [10]. The heart of a chicken embryo in the tabular phase closes its light entirely in the contraction phase, as shown by high-resolution M-mode echocardiography studies and optical coherence tomography $[11,12]$. Human heart movements can be visualized and recorded using B-mode and M-mode echocardiography after 5 weeks of gestation. In the embryonic stage, the atria are more likely to generate a greater force of contraction than the ventricles. Based on Doppler studies on human embryos, a monophasic inflow into the ventricles in the embryonic phase was found, which may indicate poor compliance of the heart chambers in the embryonic phase. A biphasic inflow into the ventricles was recorded in studies from 10 weeks of gestation [13]. Multicentre studies on 97 foetuses aged 6-10 weeks focused more specifically on the problem of the vestibular function in the embryonic phase, suggesting that 
A

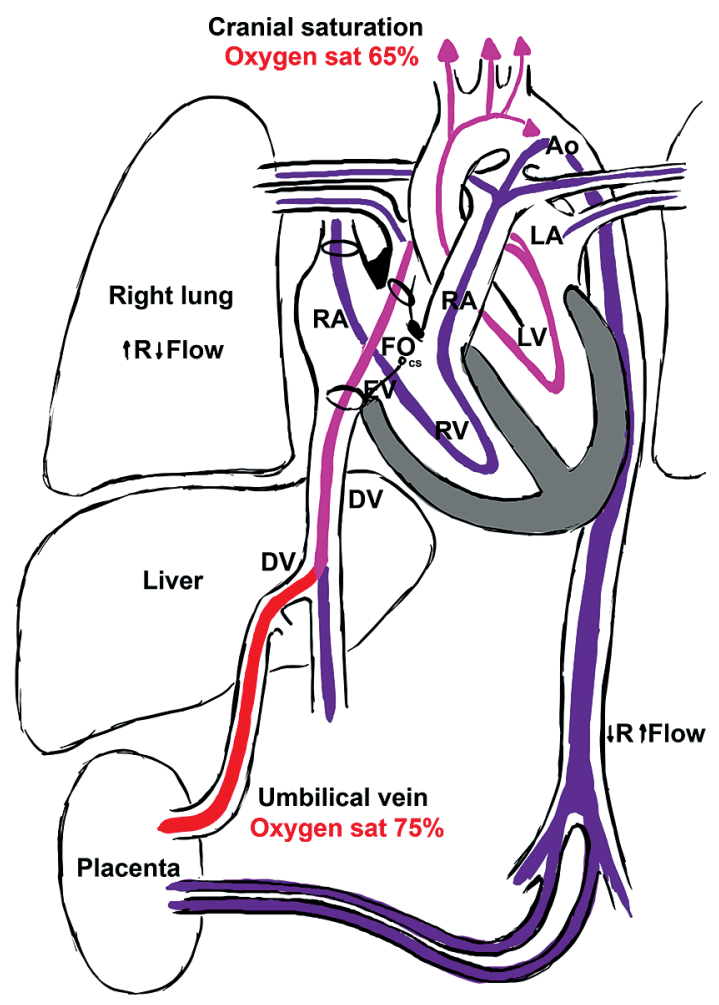

B

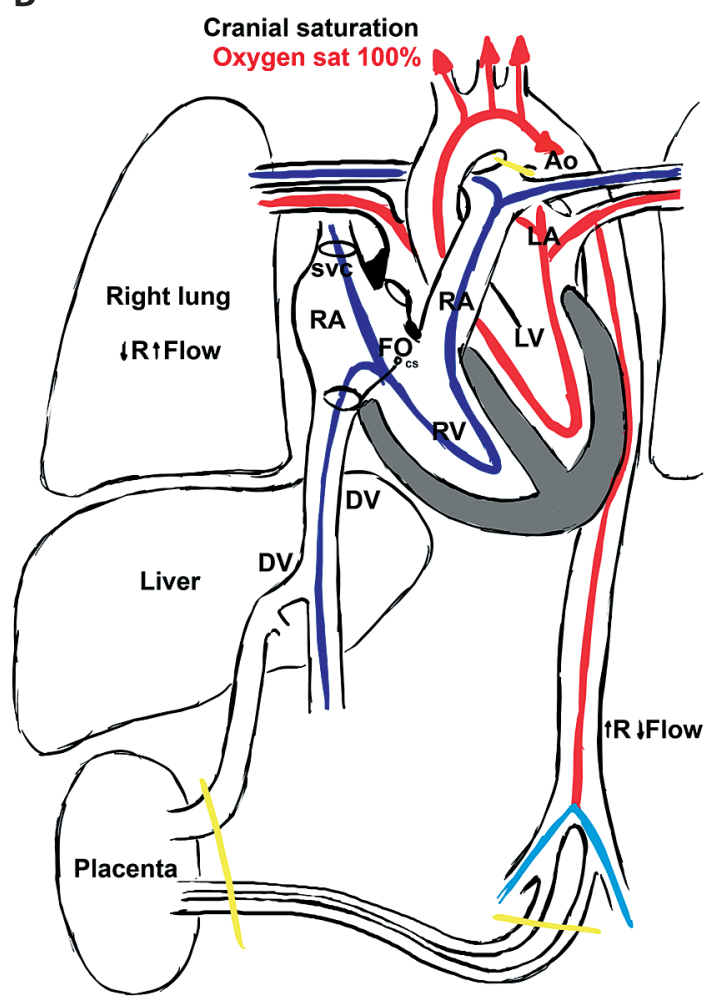

FIGURE 2. A diagram of normal fetal and neonatal cardiovascular circulation. A) Fetal circulation. Fetal blood from the placenta (oxygenated and nutrient-rich) passes via the umbilical vein. Approximately half of this blood bypasses the liver via the ductus venous (DV) and enters the inferior vena cava (IVC). The DV acts as a specific bypass in the fetal period, preferentially directing the blood flow from the right atrium (RA) through the foramen ovale (F0) to the left atrium (LA). The blood entering the RA from the IVC passes with higher velocity than that from the superior vena cava (SVC). Moreover, it is preferentially directed by the IVC (Eustachian) valve towards both the F0 and the LA. The blood from the SVC enters the RA, passes to the RV and then moves into the PA trunk. Most of this blood enters the aorta via the DA. The partially oxygenated blood in the aorta returns to the placenta via the UA. B) Neonatal circulation. At birth, with the onset of breathing, the lung replaces the placenta as the organ of gas exchange. Blood becomes oxygenated at the lungs and then returns to the LA via the PV. The F0 and the DA close, eliminating the fetal right-to-left shunts. The pulmonary and systemic circulations in the heart become separate

$D V$ - ductus venosus, UV - umbilical vein, IVC - inferior vena cava, RA - right atrium, RV - right ventricle, LA - left atrium, FO - foramen ovale, SVC - superior

the atria of the embryo, rather than the ventricles, play the dominant-systemic function [14].

\section{PHYSIOLOGY OF THE ATRIAL SEPTUM IN THE SECOND TRIMESTER}

A common feature of foetal and neonatal circulation is a preference for oxygenated blood to flow into the heart and the central nervous system. However, the method of securing the supply of oxygenated blood to vital organs is different in terms of the direction of the blood flow and the structures responsible for securing this flow. In utero, the venous conduit directs the bloodstream directly into the lumen of the foramen ovale, preferentially directing the flow of oxygenated blood from the placenta. The ductus venosus can be defined as a specific left atrial bypass (Fig. 2). In the right atrium, blood is split into 2 bloodstreams at different flow rates, with the preferential route of the faster bloodstream from the IVC through the FO to the LA. Thanks to this, oxygenated blood is directed from the left atrium to the left ventricle, the aorta, and cerebral circulation vessels [15]. The remaining portion of the septum primum acts as the valve of the foramen ovale. Blood cannot flow in the opposite direction because the muscular strength of the septum secundum prevents prolapse of the septum primum [5]. A feature that is only characteristic of the foetal period is assuming the shape of a spinnaker - a bulging of the primary valve in the LA lumen. The aneurysm description of this FO valve is also characteristic of the foetal period and is due to the increased pressure in the right atrium (RA). Prenatal diagnosticians pay attention to the aneurysmal $\mathrm{FO}$ valve because of the increased risk of benign foetal arrhythmias resulting from mechanical irritation of the RA. The spinnaker effect or the FO aneurysm cease to be a problem at delivery. Hence, there may be some misunderstandings in the interpretation of the image by paediatric cardiologists who do not see this type of abnormality during infancy. The right venous sinus valve is an additional anatomical structure that helps to direct oxygenated blood flowing from the venous duct, through the inferior vena cava, towards the foramen ovale. In 
the postnatal period, this structure remains in the form of a valve in the inferior vena cava (the Eustachian valve). Sometimes, the right venous sinus valve grows excessively and forms a Chiari network in the lumen of the right atrium. Another anatomical structure to differentiate from the Eustachian valve that may remain in the right atrial lumen after birth is the coronary sinus valve, referred to as the Thebesian valve [16].

\section{PHYSIOLOGY OF THE ATRIAL SEPTUM IN THE THIRD TRIMESTER}

The prenatal period is characterized by the possibility of assessing the foramen ovale and the contractility of both atria simultaneously. Only in this period of life is it possible to visualize the movement of the atrium walls in relation to each other in the M-mode projection. A typical pattern of M-mode echo RA/LA was found in which the septum primum (the FO flap) was always moving within the space of the LA, presenting a typical trace: during atrial wall contractions it was moving fast towards the RA wall, and during atrial diastole it showed a slower biphasic trace [17].

Premature closure of the foramen ovale in the foetus is an extremely rare anomaly with a high risk of intrauterine death. The image of closing the foramen ovale is dominated by the image of right ventricular failure: cardiomegaly, an exudate in the pericardium, and a thickening of the atrial septum. Termination of pregnancy by caesarean section may ensure the survival of the newborn $[18,19]$.

\section{TRANSITION OF THE ATRIAL SEPTUM FROM THE FOETAL TO NEONATAL PERIOD}

The process of transition from foetal to neonatal circulation is very dynamic. The foetus prepares for this change at the end of pregnancy by increasing blood distribution and reducing resistance in the pulmonary bed [20]. A disruption of this process during pregnancy may contribute to the clinical manifestations of pulmonary hypertension, respiratory distress syndrome, or transient tachypnoea of the newborn (TTN) [21]. The first minutes after birth, but before clamping the umbilical cord, are very important. Delayed umbilical cord clamping is associated with significant neonatal benefits in infants, including improved transitional circulation, higher saturation in the first minutes of life, a lower heart rate, and earlier establishment of breathing [22]. At birth, with the onset of breathing, the lung replaces the placenta as the organ of gas exchange. The pulmonary blood flow increases from $21 \%$ of the combined ventricle output to the total cardiac output in the human infant [23]. After the establishment of respiration, the pulmonary arterial pressure gradually decreases while the systemic pressure increases. The mean pulmonary arterial pressure approaches $50 \%$ of the mean systemic pressure by the end of the first day, and then drops to the adult level within the first 2 weeks of life $[23,24]$. As soon as the systemic pressure and resistance become greater than those in the pulmonary circulation, the foramen ovale closes (Fig. 2).

Echocardiography performed during the first 24 hours after birth may reveal bidirectional flow at the foramen ovale level and the ballot valve of the foramen ovale, the linear outline of which is alternately visible in the right or left atrium (Fig. 3). Only right-left blood leakage in the neonatal period is associated with clinical overt central cyanosis. The factors that can cause right-left blood leakage through the foramen ovale include the conditions that increase the pressure in the right atrium and open the foramen ovale valve, such as respiratory arrest,

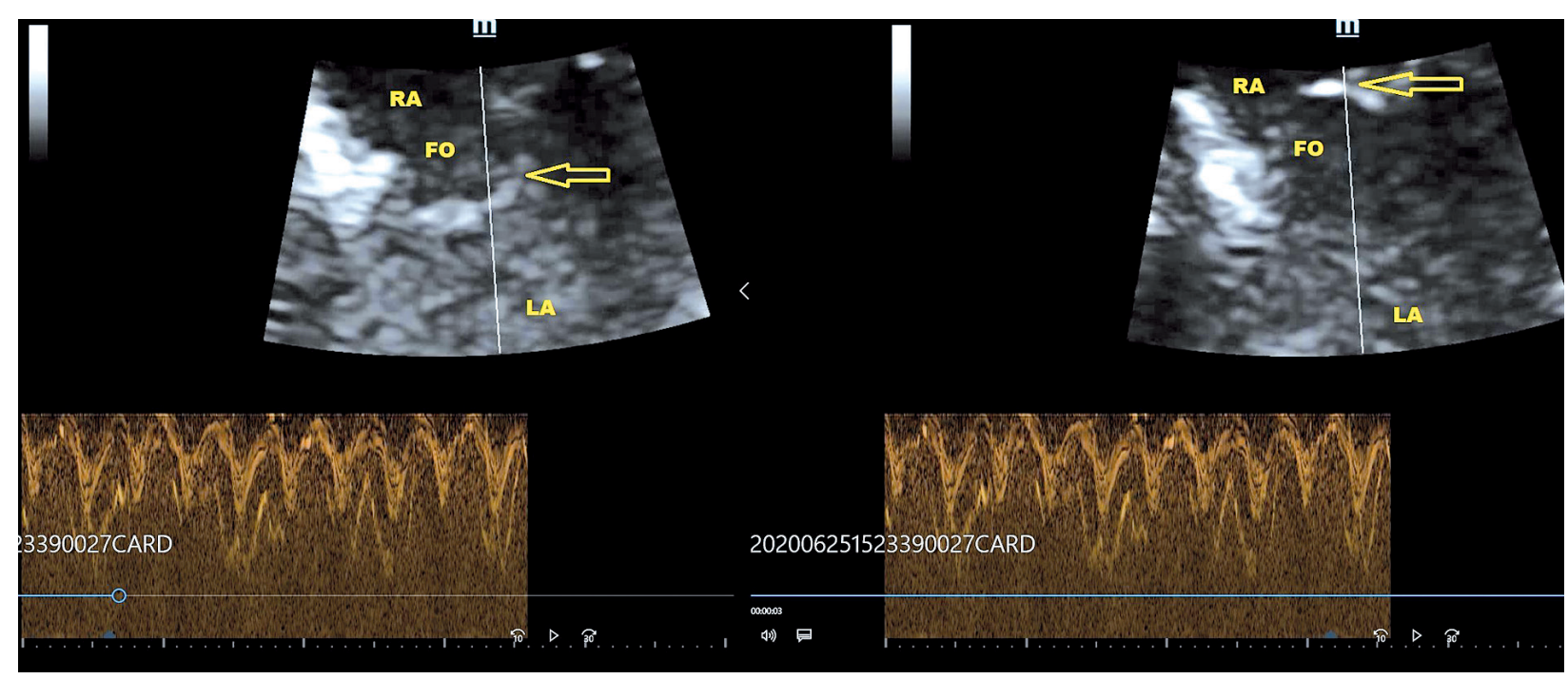

FIGURE 3. A premature infant, 27 weeks, on the $2^{\text {nd }}$ day of life, mechanical ventilation, bidirectional flow at the foramen ovale level with the F0 balloting valve. The valve flap (marked by the arrow) is visible once in the right atrium and once in the left atrium lumen. During atrial wall contractions, it is seen to be moving fast towards the LA wall, and during atrial diastole, it shows a slower monophasic trace. A confirmation of the valve flap movement in M-mode 
TABLE 1. The interpretation of the echocardiographic image at the foramen ovale level depending on the life span (fetal vs. neonatal)

\begin{tabular}{|c|c|c|c|}
\hline Feature & Variants & Foetal circulation & Neonatal circulation \\
\hline Circuits & & Parallel & Series \\
\hline Site of gas exchange & & Placenta & Lungs \\
\hline Shunts & & DV, DA, F0 & $\begin{array}{c}\text { Closure of shunts } \\
\text { DV }{ }^{\circledR} \text { ligamentum venosum } \\
\text { DA }{ }^{\circledR} \text { ligamentum arteriosum } \\
\text { F0 }{ }^{\circledR} \text { fossa ovalis }\end{array}$ \\
\hline Perfusion rate $\mathrm{ml} / \mathrm{kg} / \mathrm{min}$ & & $450-500$ & 200 \\
\hline Vascular resistance & & Pulmonary > systemic & Systemic > pulmonary \\
\hline F0 diameter & & $3-6 \mathrm{~mm}$ & Up to $5 \mathrm{~mm}$ \\
\hline \multirow{3}{*}{$\begin{array}{l}\text { Position of the flap valve } \\
\text { of the foramen ovale }\end{array}$} & LA & Normal & PPHN \\
\hline & balloting & Requires observation to explain & $\begin{array}{l}\text { Physiology in the first days of life; the persisting condi- } \\
\text { tion requires explanation }\end{array}$ \\
\hline & RA & Pathology & Normal status in the neonatal period \\
\hline \multirow[t]{3}{*}{$\begin{array}{l}\text { Blood flow direction through } \\
\text { the foramen ovale }\end{array}$} & R-L & Normal & $\begin{array}{c}\text { Pathology: PPHN, pulmonary distress syndrome, } \\
\text { asphyxia }\end{array}$ \\
\hline & bidirectional & Requires observation to explain & $\begin{array}{c}\text { Physiology in the first days of life, to be clarified PPHN } \\
\text { or significant TR }\end{array}$ \\
\hline & $L-R$ & Pathology & Physiology in the first months of life \\
\hline $\begin{array}{l}\text { Full atrial septum, an absent } \\
\text { flow at the foramen ovale }\end{array}$ & & $\begin{array}{c}\text { Threat of right ventricle circu- } \\
\text { latory failure, threat to the life } \\
\text { of the foetus }\end{array}$ & $\begin{array}{l}\text { A favourable process taking place in the first months } \\
\text { after birth }\end{array}$ \\
\hline
\end{tabular}

$D V$ - ductus venosus; DA - ductus arteriosus; FO - foramen ovale; $R A$ - right atrium; $L A$ - left atrium; PPHN - persistent pulmonary hypertension of the newborn; $R$ - L right-left (flow); $L-R$ left-right (flow); $T R$ - tricuspid regurgitation

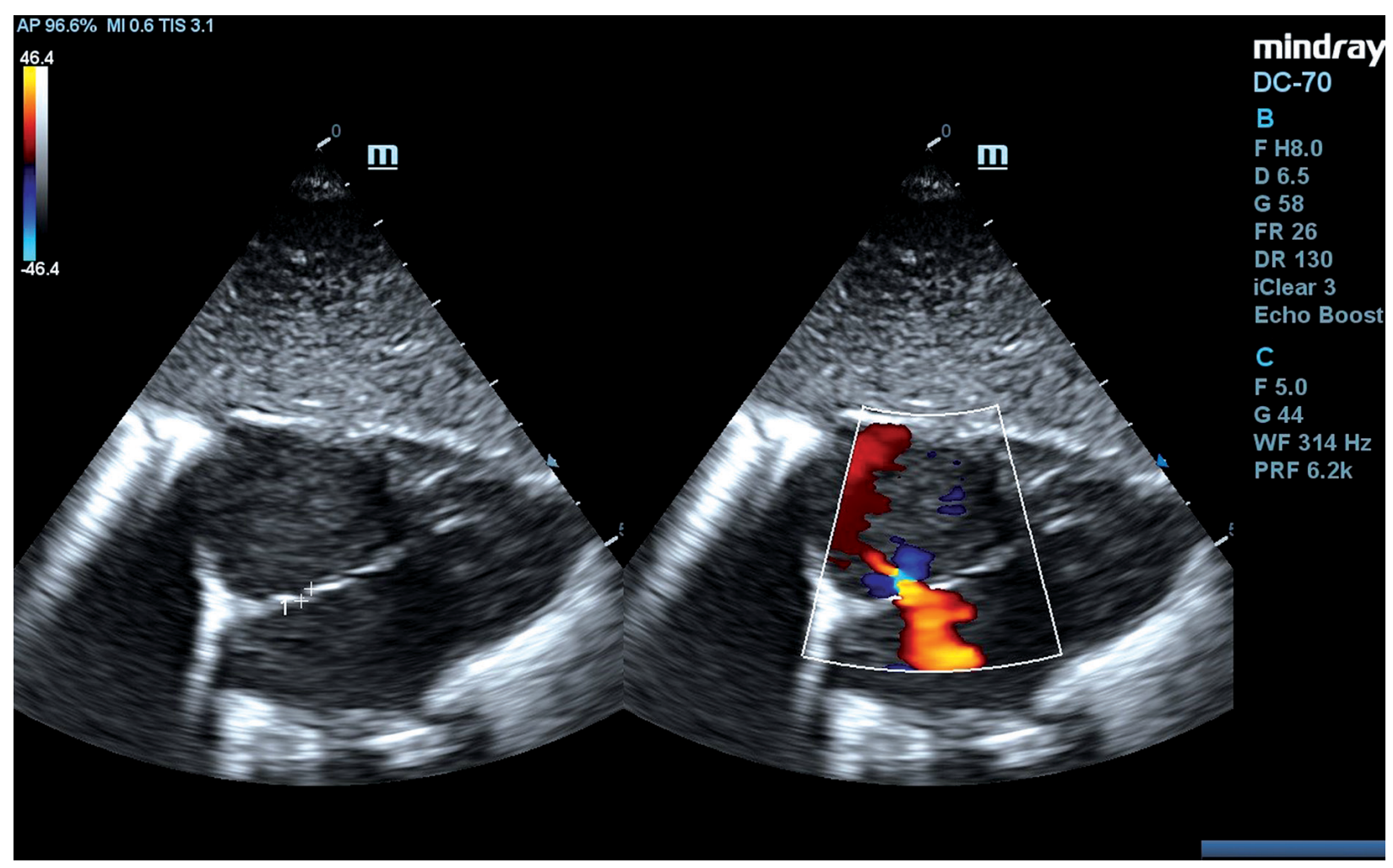

FIGURE 4. A substernal projection, an assessment of leakage at the foramen ovale level using USG color Doppler in a 2-month-old infant 


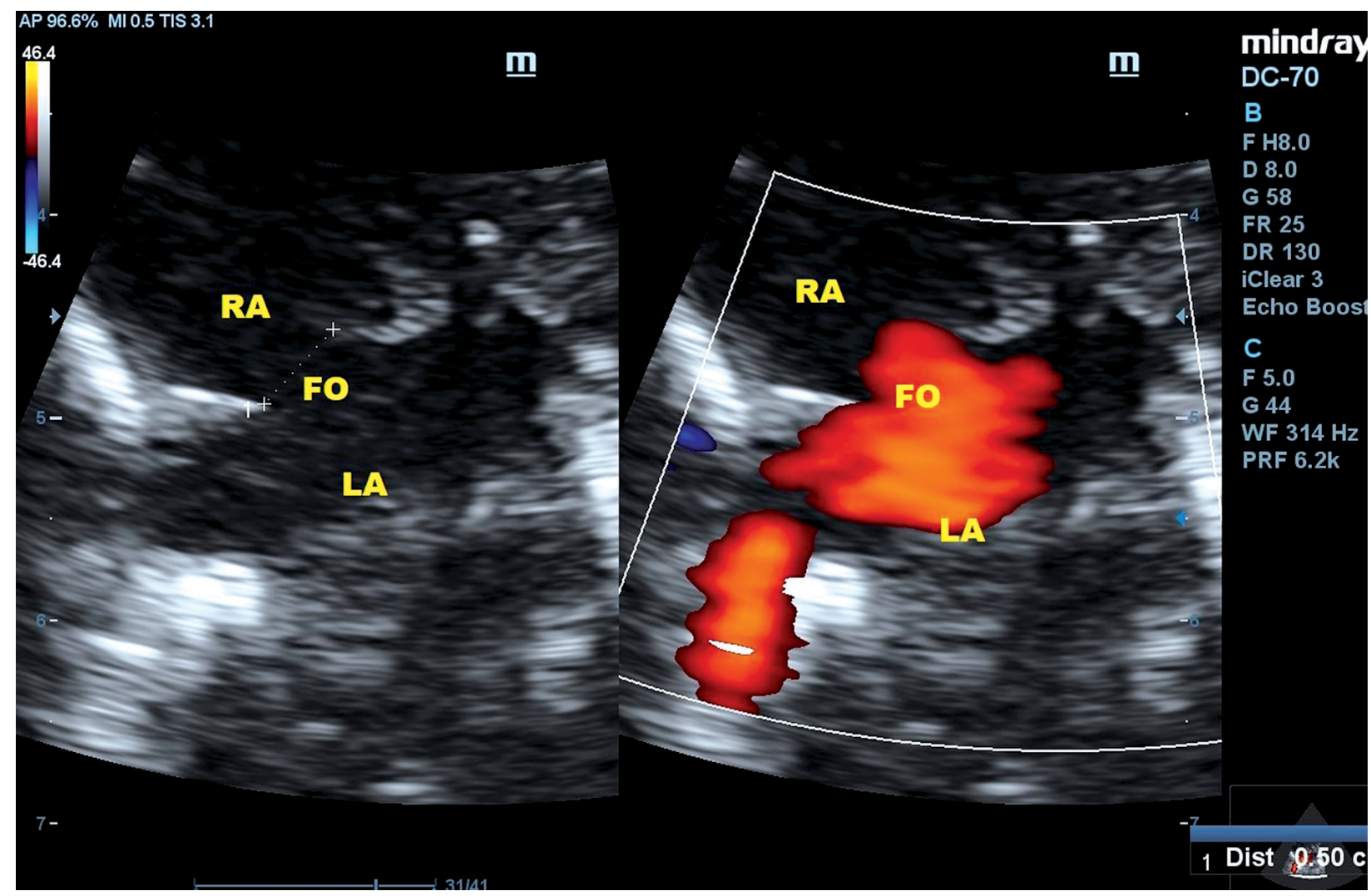

FIGURE 5. A substernal projection, measuring the orifice of the foramen ovale with the evaluation of the blood flow direction (left-right). A newborn on the $3^{\text {rd }}$ day of life

pulmonary hypertension due to other heart defects, pulmonary hypertension, or respiratory distress syndrome (Table 1). In the neonatal period, vascular shunts such as the venous and arterial ducts close within a few days of life.

The anatomical closure of the foramen ovale valve occurs until the age of 2 years, and the remainder is the oval fossa (fossa ovalis) seen from the right atrium. Nevertheless, in approximately $25-30 \%$ of the adult population, a trace of patency of the persistent foramen ovale (the patent foramen ovale - PFO) is still preserved (Fig. 5) [25]. The isolated patent foramen ovale is not associated with any haemodynamically significant leak, does not cause heart remodelling or clinical symptoms, and does not require treatment and cardiac care of children. The left-to-right shunt through the patent foramen ovale may be greater than the trace in the patients with pathologies causing septal distension, such as the left atrial enlargement seen in a haemodynamically significant patent ductus arteriosus, or a ventricular septal defect, mitral or aortic stenosis, or aortic coarctation. After the correction of these defects and the normalization of haemodynamic disturbances, the foramen ovale valve may close and the leak may disappear [26]. In the perspective of adult life, patent foramen ovale (PFO) has been associated with several disease processes including transient ischaemic attacks (TIA), cryptogenic stroke, migraine headaches with aura, platypnoea-orthodeoxia syn- drome, and shunt induced cyanosis. Stroke in association with a PFO may be due to paradoxical embolization via a right-to-left intracardiac shunt. The majority of childhood arterial ischaemic stroke and transient ischaemic attacks are associated with prothrombotic disorders or arteriopathy, and the exact contribution of PFO to stroke or stroke recurrence in childhood remains unclear. Controversy exists regarding percutaneous closure of PFO as a therapeutic treatment modality for these disease processes among the paediatric population. Therefore, the choice of treatment for PFO should be made on an individual basis, assessing the risks and benefits for each patient $[27,28]$.

\section{IMAGING OF THE FORAMEN OVALE IN THE FOETAL AND POSTNATAL PERIOD}

An assessment of blood flow through the foramen ovale is one of the most difficult elements of the foetal heart examination. Difficulties in the examination may arise from foetal movements or diaphragm movements. The flow through the foramen ovale may be obstructed by the bloodstream from the left and right outflow tract or from the pulmonary veins. The oval opening is a kind of a tunnel, so it is not enough to measure the seams in a $2 \mathrm{D}$ presentation. An assessment of the foetal valve include deflection, laxity, thickness, and M-mode recording of movement. The echo of the foramen ovale 
valve should always appear in the left atrium lumen in the M-mode presentation. If the echocardiographic examination of the foramen ovale in the third trimester of pregnancy gives a normal result and the foetus is not burdened with a heart defect, then the well-being of the foetus is carefully assessed and a good clinical condition of the newborn can be expected [17]. After birth, the defect should be visualized in several projections (sub-sternum, vascular short, 4-chamber apical) to determine its location and size, and to measure the length of the preserved flap. Using the colour-coded Doppler technique, it is necessary to register the blood flow through the defect, in order to determine the flow direction (Fig. 5) [26]. Transthoracic and especially transoesophageal echocardiography with a Valsalva manoeuvre in older children and adults is highly sensitive as a screening tool. Transthoracic echocardiography with colour Doppler and a concurrent bubble contrast study are excellent for visualizing the atrial septum and PFO and identifying a right-toleft shunt [29].

\section{CONCLUSIONS}

The structures related to the right atrium of the foetus together with the foramen ovale play a key role in the circulation of both the embryo and the foetus. The proper blood flow through this specific tunnel in the interatrial septum guarantees the proper health of the foetal circulatory system. The phenomena seen by prenatal diagnosticians, such as the so-called spinnaker valve and the aneurysmic $\mathrm{FO}$ valve, are not reflected after the birth of the newborn, because when the umbilical cord is blocked, the pressure system and the flow direction inside the heart of the newborn change dramatically. The closure of the foramen ovale in the foetus is a real threat to life, but after birth it is a desirable phenomenon. Therefore, the diagnosis of an atrial septal defect as a heart defect is reserved only for the postnatal period. The blood flow observation at the foramen ovale level is an important element in the diagnosis of the haemodynamic changes occurring in the circulatory system in both the foetus and the newborn. Patent foramen ovale is present in about a quarter of the general population and is assessed as a physiological variant. There is a lack of high-quality studies in the paediatric population confirming PFO as the cause of stroke incidents. Nevertheless, it should be borne in mind that when the patient becomes an adult, then PFO may be an indication for antiplatelet/oral anticoagulant or even transcatheter closure.

\section{DISCLOSURE}

The author declares no conflict of interest.

\section{REFERENCES}

1. Anderson RH, Spicer DE, Brown NA, Mohun TJ. The development of septation in the four-chambered heart. Anat Rec (Hoboken) 2014; 297: 1414-1429.

2. Jensen B, Wang T, Moorman AFM. Evolution and Development of the Atrial Septum. Anat Rec (Hoboken) 2019; 302: 32-48.

3. Hagen PT, Scholz DG, Edwards WD. Incidence and size of the patent foramen ovale during the first 10 decades of life: An autopsy study of 965 normal hearts. Mayo Clin Proc 1984; 59: 17-20.

4. Calvert PA, Rana BS, Kydd AC, Shapiro LM. Patent foramen ovale: Anatomy, outcomes, and closure. Nat Rev Cardiol 2011; 8: 148-160.

5. Tan CMJ, Lewandowski AJ. The transitional heart: from early embryonic and fetal development to neonatal life. Fetal Diagn Ther 2020; 47: 373-386.

6. Wessels A, Anderson RH, Markwald RR, et al. Atrial development in the human heart: an immunohistochemical study with emphasis on the role of mesenchymal tissues. Anat Rec 2000; 259: 288-300.

7. Sadler, Thomas W. Langman's Essential Medical Embryology. Lippincott Williams \& Wilkins, Philadelphia 2004.

8. Männer J, Wessel A, Yelbuz TM. How does the tubular embryonic heart work? Looking for the physical mechanism generating unidirectional blood flow in the valveless embryonic heart tube. Dev Dyn 2010; 239: 1035-1046.

9. Hiermeier F, Männer J. Kinking and Torsion Can Significantly Improve the Efficiency of Valveless Pumping in Periodically Compressed Tubular Conduits. Implications for Understanding of the Form-Function Relationship of Embryonic Heart Tubes. J Cardiovasc Dev Dis 2017; 4: 19.

10. Longatti P. The Liebau phenomenon: a translational approach to new paradigms of CSF circulation and related flow disturbances. Childs Nerv Syst 2018; 34: 227-233.

11. McQuinn TC, Bratoeva M, Dealmeida A, et al. High-frequency ultrasonographic imaging of avian cardiovascular development. Dev Dyn 2007; 236: 3503-3513.

12. Yelbuz TM, Choma MA, Thrane L, et al. Optical coherence tomography: a new high-resolution imaging technology to study cardiac development in chick embryos. Circulation 2002; 106: 2771-2774.

13. Acharya G, Gui Y, Cnota W, et al. Human embryonic cardiovascular function. Acta Obstet Gynecol Scand 2016; 95: 621-628.

14. Wloch A, Rozmus-Warcholinska W, Cnota W, et al. Atrial dominance in the human embryonic heart: a study of cardiac function at 6-10 weeks of gestation. Ultrasound Obstet Gynecol 2015; 46: 553-557.

15. Kiserud T, Eik-Nes SH, Blaas HG, Hellevik LR. Foramen ovale: an ultrasonographic study of its relation to the inferior vena cava, the ductus venosus and hepatic veins. Ultrasound Obstet Gynecol 1992; 2: 389-396.

16. Paraskevas G, Koutsouflianiotis K, Iliou K. The first descriptions of various anatomical structures and embryological remnants of the heart: A systematic overview. Int J Cardiol 2017; 227: 674-690.

17. Respondek-Liberska M. Fetal M-mode echocardiography of the atria in normal heart anatomy and no functional abnormalities. Prenat Cardio 2020; (1): 19-23; doi: 10.5114/pcard.2020.96457.

18. Pesonen E, Haavisto H, Ammälä $\mathrm{P}$, Teramo K. Intrauterine hydrops caused by premature closure of the foramen ovale. Arch Dis Child 1983; 58: 1015-1016.

19. Kim HS, Sohn S, Park MY, Choi JY. Coexistence of ductal constriction and closure of the foramen ovale in utero. Pediatr Cardiol 2003; 24: 588-590.

20. Morin FC, Egan EA. Pulmonary hemodynamics in fetal lambs during development at normal and increased oxygen tension. J Appl Physiol 1992; 73: 213-218. 
21. Hillman NH, Kallapur SG, Jobe AH. Physiology of transition from intrauterine to extrauterine life. Clin Perinatol 2012; 39: 769-783.

22. Kc A, Singhal N, Gautam J, et al. Effect of early versus delayed cord clamping in neonate on heart rate, breathing and oxygen saturation during first 10 minutes of birth - randomized clinical trial. Matern Health Neonatol Perinatol 2019; 5: 7.

23. Gao Y, Raj JU. Regulation of the pulmonary circulation in the fetus and newborn. Physiol Rev 2010; 90: 1291-1335.

24. Rudolph AM. Aortopulmonary transposition in the fetus: speculation on pathophysiology and therapy. Pediatr Res 2007; 61: 375-380.

25. Morton SU, Brodsky D. Fetal physiology and the transition to extrauterine life. Clin Perinatol 2016; 43: 395-407.

26. Janiec I, Kucińska B, Werner B. The patent foramen ovale and the secondary-type atrial septal defect - importance and management in children. New Pediatrics 2016; 1: 20-25.

27. Choi DY, Shin DH, Cho KH, et al. Migraine with aura: A predictor of patent foramen ovale in children and adolescents. Cephalalgia 2013; 33: 63-68.

28. Wawrzyńczyk M, Gałeczka M, Karwot B, et al. Efficiency of transcatheter patent foramen ovale closure in children after paradoxical embolism events. Kardiol Pol 2016; 74: 385-389.

29. Khan R, Chan AK, Mondal TK, Paes BA; Thrombosis and Hemostasis in Newborns (THIN) Group. Patent foramen ovale and stroke in childhood: A systematic review of the literature. Eur J Paediatr Neurol 2016; 20: 500-511. 